\title{
Ethnomedicinal uses of Hagenia abyssinica (Bruce) J.F. Gmel. among rural communities of Ethiopia
}

\author{
Biruktayet Assefa ${ }^{1 *}$, Gerhard Glatzel ${ }^{1}$, Christine Buchmann²
}

\begin{abstract}
Ethiopian communities highly depend on local plant resources to secure their subsistence and health. Local tree resources are exploited and used intensively for medicinal purposes. This study provides insight into the medicinal importance of Hagenia abyssinica as well as the degree of threat on its population. An ethnobotanical study was carried out to document medicinal uses of Hagenia abyssinica by rural communities of North and Southeastern Ethiopia. The study was conducted using an integrated approach of group discussions, observation, a local market survey and interviews. A total of 90 people were interviewed among whom elderly and traditional healers were the key informants. Societies in the study sites still depend on Hagenia abyssinica for medicine. All plant parts are used to treat different aliments. Tree identification, collection and utilization were different among the studied communities. In spite of its significance, interest in utilizing flowers of Hagenia abyssinica as an anthelmintic seems to be diminishing, notably among young people. This is partly because the medicine can be harmful when it is taken in large quantities. Nowadays, the widely used Hagenia abyssinica is endangered primarily due to various anthropogenic impacts. This in turn may become a threat for the associated knowledge. It is recommended to assist communities in documenting their traditional knowledge. Measures for conserving species are urgently needed.
\end{abstract}

\section{Introduction}

Plants have played a vital role in the prevention and treatment of disease since prehistoric times. People in different parts of the world depend on plant resources for their basic needs and are aware of many useful species occurring in their ecosystem. They have continuously developed their knowledge of traditional plant uses and plant resource management [1-4]. Traditional knowledge is described as 'a cumulative body of knowledge, practice and belief, evolving by adaptive processes and handed down through generations by cultural transmission, about the relationship of living beings (including humans) with one another and with their environment' [2]. In many countries of Africa, Asia and Latin America people depend on traditional knowledge and medicinal plants to meet some of their primary

\footnotetext{
* Correspondence: bickyjoe@yahoo.com

'University of Natural Resources and Applied Life Sciences, Department of Forest and Soil Sciences, Institute of Forest Ecology, Peter Jordan-Strasse 82, 1190 Vienna, Austria

Full list of author information is available at the end of the article
}

health care needs. For instance in Africa up to $80 \%$ of the population use traditional medicine for primary health care [5]. Likewise, many Ethiopian communities are dependent on local plant resources for medicine. Ethiopia is endowed with diverse biological resources due to significant geographical diversity, which favored the formation of different habitat and vegetation zones. Ethiopia is also home to a diverse mix of ethnic, cultural and linguistic groups. This diverse combination of social and cultural backgrounds contributed much to the existence of rich indigenous knowledge, including managing and using medicinal plants against human and livestock ailments. Plants have been used as a source of medicine in Ethiopia for a long time. More than $80 \%$ of the Ethiopian people are dependent on plants for their health service [6]. More than 95\% of traditional medical preparations in the country are of plant origin [7]. Medicinal plants and knowledge of their uses provide a vital contribution to human and livestock health care needs. The importance of medicinal plants to treat human and 
livestock ailments in most parts of Ethiopia is stated by various authors [8-14].

Hagenia abyssinica (Bruce) J.F. Gmel. is an important medicinal plant that societies relied on for generations for combating various ailments. $H$. abyssinica is a multipurpose dioecious tree in the plant family of Rosaceae. It is a tree growing up to $20 \mathrm{~m}$ (Figure 1). The species also occurs in Kenya, Tanzania, Uganda, Sudan, Congo, Malawi, Burundi and Rwanda. Hagenia has been used as a remedy for intestinal parasites, especially against cestodes [15]. It has served as an anthelmintic in ruminants [16] and also against tapeworms in humans $[17,18]$. Besides being a source of medicine, Hagenia has been utilized for various other purposes such as construction, furniture, fuelwood, and soil fertility management. As a result of its enormous significance, $H$. abyssinica is one of the endangered tree species in the country due to overexploitation [19]. Accordingly, the Forestry Law [20] prohibits the utilization/harvesting of Hagenia abyssinica. The proclamation was enacted with a view of providing and enhancing better conservation, development and utilization of forests. However, in practice, there is a lack of law enforcement. Consequently $H$. abyssinica population is increasingly endangered.

Habitat destruction reduces the existence of such important species, and thus negatively affects several aspects of human well-being, such as food security, medicine as well as the associated traditional knowledge. In spite of its significance, information on the traditional use of $H$. abyssinica has experienced little consideration. Studies have been conducted on medicinally important Ethiopian plant species among which $H$. abyssinica is also listed $[14,18,19,21]$. However, former studies do not provide sufficiently detailed information on the utilization of $H$. abyssinica ; hence further research is necessary. This study aims to examine in detail the traditional knowledge on the identification, harvesting, preparation and utilization of $H$. abyssinica by Ethiopian rural communities. The medicinal value of $H$. abyssinica to the rural communities is highlighted. Factors influencing current utilization rates are identified and current

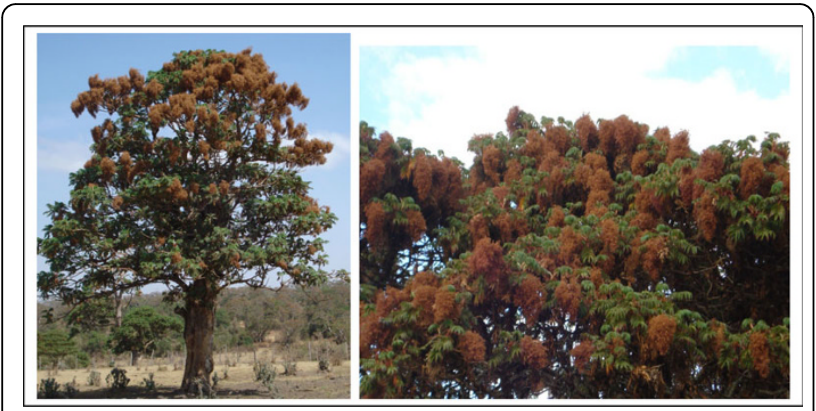

Figure 1 Standing Hagenia abyssinica tree and its flowers. management and conservation strategies examined. The first section provides an overview on description of the study sites and the methods used to document traditional knowledge. Traditional $H$. abyssinica processing and uses of various plant parts for medicinal use are described in the second part. In the concluding remarks the importance of $H$. abyssinica, as well as the degree of threat on its population and local conservation efforts are highlighted. Suggestions to promote sustainable utilization of Hagenia abyssinica are presented.

\section{Methodology \\ Study areas}

The study was conducted in three different parts of the country (Figure 2). The study sites were chosen systematically so as to conduct both ecological and social studies on Hagenia abyssinica. The social part is presented in this paper while the ecological field data will be published in a separate paper. The study site 'Milligebsa' (hereafter described as Debark) is located in Amhara Regional State, Northern Ethiopia which is in $18 \mathrm{~km}$ distance from Debark town. The geographic location is $13^{\circ}$ $11^{\prime} \mathrm{N}$ and $37^{\circ} 58^{\prime} \mathrm{E}$. The altitude ranges between 2800 $\mathrm{m}-3150 \mathrm{~m}$ a.s.l. The mean annual rainfall ranges between $900-1400 \mathrm{~mm}$. The minimum temperature usually drops to $-3^{\circ} \mathrm{C}$ and $-5^{\circ} \mathrm{C}$ at night. Soil type is characterized as Haplic Cambisols of silty clay texture. The people in the study site are Amharas who are engaged with subsistence farming and livestock rearing. Amharic is the language spoken. The second study site is a small village called 'Deyu' (hereafter described as Kofele) which is located in Oromiya National Regional State, Southeastern Ethiopia. It is in $5 \mathrm{~km}$ distance from Kofele town. It is located between $7^{\circ} 11^{\prime} \mathrm{N}$ and $38^{\circ} 52^{\prime} \mathrm{E}$. The area lies between $2600 \mathrm{~m}$ and $2750 \mathrm{~m}$ a.s.l. Annual average rainfall is about $1232 \mathrm{~mm}$ with a mean monthly rainfall of $102.6 \mathrm{~mm}$. The mean monthly minimum and maximum temperature is about $5.4^{\circ} \mathrm{C}$ and $19.8^{\circ} \mathrm{C}$ respectively [22]. The soil is characterized as Haplic Luvisols of clay texture. Vegetation is mostly composed of perennial grasses and tree species. The Oromos are the dominant people residing in the area, among other ethnic groups. Oromiffa is the local language spoken. Most are small holder subsistence farmers engaged with agriculture and animal rearing.

The third study site 'Dinsho' (hereafter described as Bale) is located in the Bale Mountains National Park (BMNP). It is also set in Oromiya National Regional State, in Southeastern Ethiopia, and lies within the geographical coordinates of $7^{\circ} 06^{\prime} \mathrm{N}$ and $39^{\circ} 47^{\prime} \mathrm{E}$. The altitude lies about $3200 \mathrm{~m}$ a.s.l. The area has a bimodal rainfall characterized by a rainy season lasting from March to October and a dry season that extends from November to February [23]. Mean annual rainfall is 


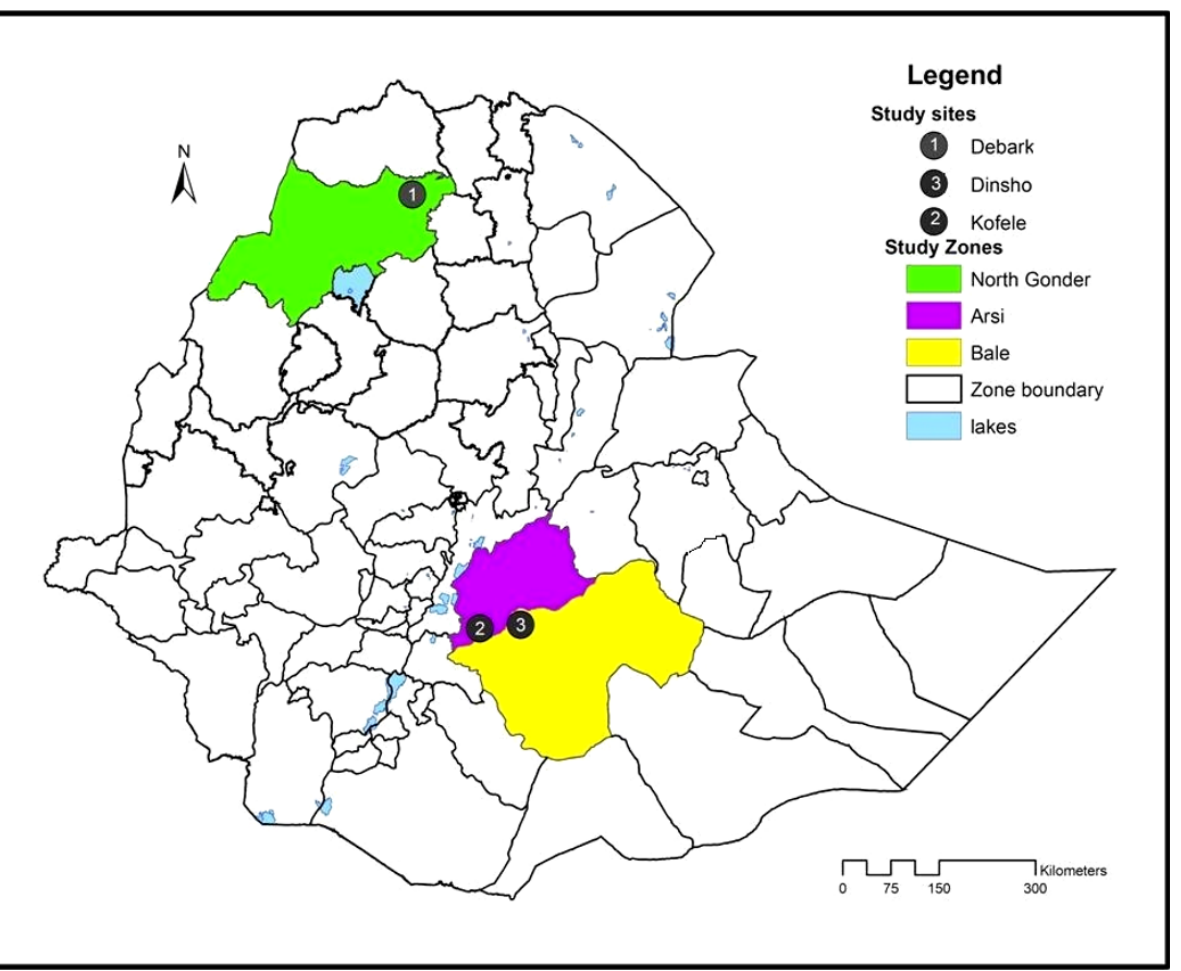

Figure 2 Location of the study sites.

about $1218.6 \mathrm{~mm}$. The mean annual minimum, and maximum temperature is $2.4^{\circ} \mathrm{C}$ and $15.5^{\circ} \mathrm{C}$, respectively. The present topography is a reflection of long term weathering processes originating from Oligocene lava outflows [24]. Soil in the study site is characterized as Mollic Andosols with silty clay texture. The Oromos are the dominant ethnic group living in the area, among other ethnic groups. Oromiffa is the local language spoken. Main economic activity is based on mixed farming which involves pastoralism and cultivation of crops.

\section{Data collection and analysis}

Prior to data collection, a preliminary field survey was carried out in March 2008. The intensive data collection was subsequently conducted in three phases. Communities in the Kofele area were interviewed in the $1^{\text {st }}$ phase, from April to May 2008. The $2^{\text {nd }}$ phase (June July 2008) was allocated to communities living in the Bale Mountains National Park. Communities in Debark area were interviewed during the $3^{\text {rd }}$ phase (August-September 2008). Methods used to document the traditional knowledge included interviews, observation, and open group discussions with local communities. In addition, a local market survey was conducted. A total of 90 people (30 from each site) were chosen systematically following [25]. Informants were chosen with the help of elderly people and local administrators in the study sites. Semi-structured interviews were conducted following [26]. At Bale and Kofele sites the interviews were conducted in the Afaan Oromo language. Though the corresponding author understood the language at times a local translator assisted in the interview process. The interviews in the Debark site were conducted in Amharic language. Each informant was interviewed separately and advised not to discuss with each other so that they could provide independent information. Interviews were conducted in places such as school compounds, providing a comfortable space to all. Before conducting the interviews, informants were briefed about the aims of the study and gave prior informed consent. Where applicable the International Society of Ethnobiology (ISE) code of ethics [27] were respected. Questions were asked in a stepwise manner by first asking relevant data on their age, sex, address, level of education and occupation. Following to that, informants were asked to share their knowledge on the utilization of Hagenia abysinica . This included: how long and for what purpose they have been using $H$. abyssinica, plant parts used, preparation methods, form used (fresh/dried), mode of application, as well as identification, collection and utilization. Respondents were asked to state the status/degree of scarcity of the species, factors affecting the current utilization rate and if there were any management and conservation activities taking place in the 
Table 1 Local name of male and female Hagenia abyssinica trees

\begin{tabular}{lllll}
\hline Study site & Local language & Local name of Hagenia abyssinica & Local name for male tree & Local name for female tree \\
\hline Kofele & Oromiffa & Heto & Balfe & Hatiya \\
& & & Artu \\
\hline Bale & Oromiffa & Heto & Gurumbo & Degemele \\
& & & Korma & Artu \\
\hline Debark & Amharic & Kosso & Wende & Sete
\end{tabular}

area. In addition, observation and in-depth interviews with key informants, such as elderly and traditional healers, formed part of the field research. As this study is conducted along with an ecological study of $H$. abyssinica a number of plant species were encountered in the study areas. All plant specimens including those mentioned in the present study were identified at the National Herbarium, Addis Ababa University, where voucher specimens were deposited. Data were organized in Excel (Microsoft 2003) datasheets. Responses given by respondents were coded into numerical form for the analysis (e.g. 1 = Yes, 2 = No) and simply presented as percentages.

\section{Results and discussion}

Tree identification

Informants in all sites knew Hagenia abyssinica , many of them since their childhood. Hagenia is a dioecious species with separate male and female trees that are identified under different local names (Table 1). Trees with bright pinkish-red inflorescence and bulkier flower heads are considered to be female and the ones with yellowish color and feathery flower heads are regarded as male trees $[28,29]$. About 13 respondents in Debark (7 male respondents), 20 in Bale (17 male), and 24 in Kofele (13 male) site stated that they are able to differentiate between male and female trees.

\section{Plant part collection}

Informants stated different times as the 'best time' for plant collection. In Kofele for example, the best time to collect the inflorescence is from October to February; while in Bale it is from October to end of January. People in Debark site collect in November and December. Collection during these months is interrelated with the fruiting and flowering phenology of $H$. abysinica . Apart from the inflorescences, collection of other plant parts (e.g. root, bark) can be carried out any time.

Table 2 Medicinal value of parts of $\boldsymbol{H}$. abyssinica in the study sites

\begin{tabular}{|c|c|c|c|c|}
\hline \multicolumn{5}{|c|}{ BALE } \\
\hline Bark & Flower & Root & Leaf & Wood \\
\hline Fever/cough & $\begin{array}{l}\text { Intestinal worms (tape } \\
\text { worm) }\end{array}$ & Stomachache & Diarrhea & $\begin{array}{l}\text { Stomachache (reddish color liquid } \\
\text { from the sapwood) }\end{array}$ \\
\hline Stomachache & For healing wound & & Typhoid & \\
\hline Cold (bronchitis) & Epilepsy* & & Cough & \\
\hline $\begin{array}{l}\text { Livestock disease (thin/ } \\
\text { skinny body) }\end{array}$ & Evil eye & & $\begin{array}{l}\text { Livestock disease (mixed with } \\
\text { Juniperus procera) }\end{array}$ & \\
\hline \multicolumn{5}{|c|}{ KOFELE } \\
\hline Bark & Flower & Root & Leaf & Wood \\
\hline Dermatology & $\begin{array}{l}\text { Intestinal worms (tape } \\
\text { worm) }\end{array}$ & Stomachache & Diarrhea & $\begin{array}{l}\text { Stomachache (reddish color liquid } \\
\text { from the sapwood) }\end{array}$ \\
\hline Malaria & Hepatitis* & Severe abdominal pain & Livestock disease & \\
\hline Stomachache & $\begin{array}{l}\text { Sexually Transmitted } \\
\text { Diseases (STDs) }\end{array}$ & Throat disease & & \\
\hline Livestock disease & Problems related to Bile & $\begin{array}{l}\text { Cancer (mixed with } \\
\text { other plants)* }\end{array}$ & & \\
\hline \multicolumn{5}{|c|}{ DEBARK } \\
\hline Bark & Flower & Root & Leaf/seeds & Wood \\
\hline Livestock disease & $\begin{array}{l}\text { Intestinal worms (tape } \\
\text { worm) }\end{array}$ & Severe stomach pain & $\begin{array}{l}\text { For healing injured part } \\
\text { (human/livestock) }\end{array}$ & \\
\hline
\end{tabular}

\footnotetext{
* Information obtained from traditional healers
} 
Respondents further stated that though it is possible to collect plant part at any time of a day, but it is more preferable to do it in the morning. This is associated with the effectiveness of the medicine. Sixty percent of respondents in Kofele, $42 \%$ in Bale and 22\% percent in Debark site explained that parts of $H$. abyssinica collected in the morning time could have strong and effective medicinal properties to treat any ailment. Common technique to collect plant parts includes climbing the tree, which is usually done by children. Leaves on lower branches, as well as pieces of bark, are gathered by hand while roots are collected by digging. People in Bale and Kofele areas used forked branches of trees and bamboo sticks to collect the inflorescence part. In the same study site people carefully cut the tree trunk to obtain the sap. In Debark people use Kezera (a walking stick) for collecting the inflorescences. The amount of plant parts collected by the people depends on the uses. A family collects a small quantity if the use is aimed for domestic purposes. For example, to prepare a self-made remedy against intestinal ailments, a small amount of plant parts (mostly the inflorescence) is collected. Alternatively, several sacks could be collected if intended to be sold on the local market.

\section{Plant utilization}

Utilization of $H$. abyssinica was stated as significant to the communities of all study sites. This confirms its considerable value to different societies of the country which is also stated in the literature $[9,13,29,35]$. This particular study confirms that parts of $H$. abyssinica are used against several human and livestock ailments. Medicinal uses were categorized as intestinal, digestive, circulatory, respiratory and nervous system, among others, disorders (Table 2). The anthelmintic action of $H$. abysinica against tapeworm (Taenia saginata Goeze), whose widespread occurrence grounds in the consumption of dishes containing raw beef, has been mentioned by all informants in all study sites. Hagenia has been also described as a powerful remedy for intestinal parasites, especially against cestodes $[10,11,14,15,17,30-32]$. In the $19^{\text {th }}$ century, the species was included in most European pharmacopoeias as an effective drug against intestinal worms, which made it one of the most famous African plants at that time $[33,34]$. In addition to its importance against human ailments $H$. abyssinica has anthelmintic property to treat ruminants such as cattle, goats, and sheep. Its bark and leaves are used to treat livestock diseases. Informants in Bale and Kofele explained that a decoction of bark is given to cattle and equines to treat a disease that turns livestock thin and skinny. In Debark, fresh leaves of $H$. abysinica are wrapped on fractures of equines.
Table 3 Substances mixed with powdered flowers of H. abyssinica (Kosso medicine)

\begin{tabular}{ll}
\hline Substance & Study site \\
\hline Cold water & A, B, C \\
Warm water & A, B, C \\
Milk & A, B \\
Arera (sour defatted milk) & A, B \\
Aguwat (whey) & A, B \\
Honey & A, B, C \\
Banana & A, B, C \\
Kebericho (Echinops kebericho Mesfin) & A \\
Dobi (Girardinia bullosa (Steudel) Wedd.) & A, B \\
Hinkoko (Embelia schimperi Vatke) & A, B, C \\
Cabbage (Brassica oleracea L.) & A \\
Pumpkin (Cucurbita pepo L.) & A \\
\hline
\end{tabular}

Key: $\mathrm{A}=$ Bale; $\mathrm{B}=$ Kofele; $\mathrm{C}=$ Debark

Medicinal uses of Hagenia against livestock ailments have been also documented in literature $[14,16,30,35]$.

\section{Mode of preparation}

In general, plant parts of Hagenia are processed either in fresh or dried forms. Children or elder people collect the plant part which is intended for remedy preparation. Usually elderly men are responsible for harvesting the bark and root part. The process of preparing medicine from female flowers (here after called as kosso ) is simple yet requires care. Normally the name kosso refers to the tree itself (in Amharic), the human tapeworm (Taenia saginata Goeze) or the medicine. Kosso preparation comprises different steps, and considers details like which part needs to be used, amount and substances to be mixed (if any), and time to prepare the solution. For the preparation the flower is sun-dried so that it can easily be separated from the whole inflorescence. In Bale, the whole inflorescence is covered for 1 or 2 days with animal skin (pelt usually from a cow or an ox) or with leaves of Discopodium penninervium Hochst, and later kept in the sun for further drying. After drying the flower is roasted on an iron plate and pounded using a pestle and mortar. Traditional stone grinders are also used in all of the study sites. Usually women are responsible for this job. A small amount of dried flowers is ground into a powder and then sieved. Afterwards the fine powder is kept in a bowl. In Bale, women keep the powder in traditionally made materials such as Chocho (milking pail), Tunto or Kila (type of bowl usually made to keep butter). Eventually, the fine powder is mixed with different substances (Table 3) and then consumed. In Kofele and Bale areas the preparation of kosso is usually carried out during the night. In these sites the remedy has to ferment for some time. The shortest 
possible fermentation time usually takes 1-2 nights. However, in places like Bale it can be kept for about 10 days due to the cooler climate. Informants noted that keeping the remedy for a longer time helps to reduce bitterness and increase the effectiveness of the medicine. On the contrary, the medicine was prepared early in the morning and instantly consumed in Debark. On average, the preparation takes 30-60 minutes.

\section{Means of application}

In all of the study sites, kosso is usually taken orally in the form of a decoction. However, it can also be consumed in the form of paste (e.g. by mixing the powdered flower with banana or honey). Usually children and very weak patients prefer to swallow the sweet paste as the medicine is bitter. Respondents in Bale mentioned that kosso can be consumed with Dobi warabechaa (Girardinia bullosa (Steudel) Wedd), or pumpkin (Cucurbita pepo L .) seed, or cabbage (Brassica oleracea L .) or 'Hinkoko' (Embelia schimperi Vatke). Fruits of Embelia schimperi Vatke are usually grinded, macerated in water and mixed with the already prepared kosso solution. Another ethnobotanical study conducted in the region [29] reported that people in 'Dheeraa' town, Ethiopia, mix a pounded flower of Hagenia abyssinica with the root of Croton macrostachyus Hochst. ex Del. or leaf of Grewia ferruginea Juss. for worm expulsion. Respondents in the present study sites believe that mixing the two medicines could result in great medicinal effect against taeniasis, help reduce bitterness of the medicine as well as nausea. Informants in Debark also added that kosso (in paste form) can be taken with Kita, a kind of bread which is made from unleavened dough of Teff (Eragrostis teff (Zucc.) Trotter).

All respondents stated that kosso needs to be consumed in the morning on an empty stomach. The patient is not allowed to eat after taking the medicine until the proglottids (segments) are expelled from the intestine. They further noted that kosso medicine would be more effective when the proglottids are made to starve. Preventing a patient from eating for sometime is also mentioned [36]. Informants in the study sites stated that after having consumed kosso , people usually experience nausea, stomach/abdominal pain and continuous diarrhea which may last for about 6 hours, and these side effects are considered to be normal in the community. Usually after 4 to $5 \mathrm{hrs}$ segments of the worm are expelled. The patient is then provided with a warm meal, such as porridge, meat soup or Shiro (sauce made of powdered peas (Pisum sativum L.) with 'Injera' (thin flat bread made of Teff cereal). All respondents in Debark stated that by no means is the patient allowed to drink tella (locally made beer), because the interaction reduces the effectiveness of the medicine. Societies in Debark believe that kosso medicine would be effective if it is prepared by a virgin girl, a sterile woman or menopausal woman in her menopause. Apart from oral intake, dermal application is also practiced in Debark site.

Currently, kosso medicine is being utilized by the communities of all study sites. Forty three percent of respondents in Bale, $40 \%$ in Kofele and 30\% in Debark explained that this self-made remedy is widely accepted within the society as its hygienic effect gives great psychological satisfaction. Nevertheless, the prevalence of gastrointestinal upset after consumption is forcing people to reduce the intake or to change the means of preparation. Women actively take part in updating the traditional knowledge and try out different methods to reduce the side effects associated with drinking kosso . Female respondents in Bale explained that they consume kosso in the form of a decoction. A small amount of powdered flower is boiled and served in the form of tea. Another means of application included the utilization of bark in the form of smoke. Respondents in Kofele and Bale areas explained that during post partum period, mothers smoke the bark by heating it over the fire. Female respondents further stated that the practice eases muscle aches and stiff joints, stimulates blood circulation and boosts the immune system. In addition, people applied the powdered seeds on wounds and cuts of both humans and livestock.

\section{Prescription dosage, side effects and remedies against side effects}

The majority of informants explained that both selfmade, and medicines prescribed by healers need to be taken in specific doses, but they stated different amounts. Common measurement units mentioned in all communities include tea cups, water glasses and cans. Respondents explained that the dosage depends on age, sex, physical appearance of a person, health condition and severity of pain. Similar studies have also mentioned such measurements [8,36-39]. Eighty five percent of respondents in Bale, and all informants in Kofele and Debark believe that the dosage usually depends on age and sex. For instance, the smallest portion of kosso solution $(<250 \mathrm{ml})$ was usually given to very old people as well as to young boys and girls $(\sim 250 \mathrm{ml})$. In general, men consume the largest portion $(500 \mathrm{ml}$ to $750 \mathrm{ml})$ followed by women (300-500 ml). Even today, pregnant women in Bale and Kofele areas continue to drink kosso. All female respondents in these two sites explained that there was a tradition to take very small amounts $(\sim 200$ $\mathrm{ml})$. Usually when a woman starts her $3^{\text {rd }}$ or $4^{\text {th }}$ month of pregnancy she drinks kosso. Some of them continue till the $8^{\text {th }}$ month. There are also cases when a woman drinks shortly before delivery time. The women believe 
that it helps in reducing pain during delivery, and improves the health of both baby and mother. A health condition of a patient is another aspect considered before taking the medicine. They further stated that comparatively an extra amount is provided for a very ill person. In former days, it was compulsory for children to drink kosso once a month when they reached at the age of 7 or more (in Bale), 12 or more (in Kofele), and 10 or more (in Debark). The reason was by this time the children have already started eating raw meat. Overall, no age guideline is used as standard, but it is merely a decision made by the family.

Usually, medicines have some side effects, and selfmade ones are no exceptions. Informants in all study sites stated that severe stomach pain accompanied by diarrhea and occasional nausea were the usual side effects of kosso medicine. The frequency and seriousness varied greatly from patient to patient. A person may also suffer from muscular tiredness, fatigue and could even faint, if taking an overdose. The administration of an overdose may be linked to a belief that extra consumption could result in an enhanced medicinal effect; however, it has been reported that blindness and changes in the central nervous system function have been found in people who took an overdose of Hagenia abyssinica [40]. It is also reputed to cause abortion in women [41,42]. Excess dosage of kosso medicine can even cause death [41]. Despite widespread use as an anthelmintic, few reports noted that kosso medicine was found to be toxic [43]. In the present study, informants also mentioned the negative effect of kosso such as gastrointestinal upset, however, if serious problems occur due to an overdose, the person is usually provided with a remedy to counteract the side effects. This could include boiled milk, yogurt, coffee or water. In Bale and Kofele a patient was given a porridge made out of barley (Hordeum vulgare L.) flour, and a soup made of oat (Avena sativa L) or barley. Elders in Bale explained that if the pain was severe the patient was supplied with fried mutton or sheep liver. In Debark, a soup prepared from flax seeds (Linum usitatissimum L.) was usually given to the patient. The seeds were first roasted, pounded, and then boiled.

Regarding the current utilization of kosso the majority of respondents (57\% in Bale, $60 \%$ in Kofele and $70 \%$ in Debark) stated that they are currently not utilizing kosso medicine. Of this percentage, $94 \%$ in Bale, $78 \%$ in Kofele, and $81 \%$ in Debark were male respondents. This is primarily due to an increase in awareness of side effects from unknown dosage. Introduction of modern medicines and the declining of $H$. abyssinica population in the forest also play a great role. For instance, all informants in the Debark site stated that the tradition of drinking kosso still exists, but it becomes more and more difficult to collect the inflorescence as today few scattered trees exist in the area. In addition, people have realized the advantage of taking modern medicines that don't have many unwanted effects that also help them continue with their daily task without serious side effects. Respondents reported that the introduction of modern medicine has affected the value of traditional medicines in general. Low prices persuaded people to buy broad-spectrum drugs from local drug shops; however, the short supply of such drugs is a problem. Niclosamide, Mebendazole and Albendazole were among the common medicines with anthelmintic properties. These drugs have different dosages and are given to a patient based on age and/or weight. The price was about 2 to 4 ETB (equivalent to 0.18 to 0.36 USD) at the time of the field study. While conducting this study, people in Kofele area were seen buying these medicines from local drug shops. Most of them were youngsters, and they explained that modern medicines don't have many side effects and are simple and ready to be used. Moreover, those medicines don't disturb their daily work. They further highlighted that traditional medicines have not been scientifically studied or verified. They believe that traditional healers give medicines by trial and error. Traditional medicines sold on local markets were not effective due to inappropriate handling, and were mainly based on false information. Due to these reasons they prefer modern medicines over traditional ones.

\section{Traditional knowledge and its transfer}

In most developing countries, including Ethiopia, traditional knowledge on the medicinal uses of plants has been passed down from generation to generation as part of an oral tradition. Informants in all study sites stated that elder men usually share their knowledge with one of their sons, most often to the first-born. This particular son may be chosen because the father loves him very much or the son is especially keen and interested in traditional medicine [44]. This was mentioned by all male informants. Female respondents however explained that they prefer sharing their knowledge with their daughters. Traditional healers play a key role in transferring traditional knowledge in the society. Respondents explained that in need of help, it is customary to visit a traditional healer. People visit healers because they believe that healers have good knowledge of traditional medicines. In the study sites almost all of the healers were elder men. Informants explained that there are very few female healers in the area. The stated reason was that women have less interest in the practice. Men are reported to take it seriously, and for some it is even used as a base for supporting their family. Moreover, the studied communities believe that male healers have better knowledge than women, and hence the medicine 
prescribed by them is perceived to be more powerful. Such believes have resulted in the transfer of traditional knowledge mostly between the healer (men) and his children (mostly sons). In the present study sites even though female informants were few in number they were observed to have a higher level of knowledge than men regarding the detailed processing of parts of $H$. abyssinica for different medicinal purposes, especially against intestinal diseases.

By and large, in all of the study sites interest towards utilizing traditional medicine is diminishing among the younger generation. Some of the reasons mentioned include: the tendency to modern education, the migration to cities for profitable jobs, the decline of the medicinal plant population due to deforestation, and the introduction of modern medicines. Similarly, some elder people were becoming reluctant to take traditional medicines when they have already experienced severe side effects. Due to these factors, the practice is now becoming more and more outdated. This is also mentioned in another study [29]. Thus, many individuals are not willing to share their information with their children, except the knowledge related to livestock medicines. In the present study more information was obtained from elderly informants than the young ones. This could indicate a lack of interest which ultimately results in loss of knowledge. Similar studies conducted in the country also support such findings [9].

\section{Market condition}

Even though the population of Hagenia abysinica is no longer as abundant as before, its medicine is still available in local markets for a low price. Dried flowers were commonly found in all markets of the study sites. In Bale a quarter of a kilo of dried flowers was sold for about 1 ETB (equivalent to 0.1 USD). Usually small plastic cups or cans are used to measure the quantity. For one quintal the maximum price could reach up to 60-70 ETB (5-6 USD). Sometimes it may even reach up to 100ETB (9 USD). Income derived from this sale is of particular importance to the poor households, especially for women, in meeting their basic needs such as food. In Kofele market, women in their 50's were observed selling the dried flowers of Hagenia abyssinica. They explained that in the former days it was common to barter for two cups of dried flower with one cup of cereal crops like barley or wheat. In general, women, especially those who are married, or elders, were major vendors in the market. Unlike elder men young children help their mothers in selling the medicine. In line with this, healers also explained that they prepare medicine using different parts of $H$. abyssinica and its contribution to their income is considerable. Marketability of $H$. abyssinica on local markets was also mentioned in [30].

\section{Current population of Hagenia abyssinica and Conservation activities}

In Ethiopia the $H$. abyssinica population has drastically decreased due to the growing pressures from various anthropogenic factors. This study revealed that all informants in all of the study sites were aware of the scarcity of the species in their locality. Recalling their childhood times, they explained that there were plenty of $H$. abyssinica trees in the surrounding forests, but now the population has reduced significantly. Respondents in Debark site stated that the species is very scarce and only few scattered trees were left around their homes and nearby churches. Informants stated that an increase in human population, leading to settlement changes and land clearing for agriculture, was the main driving factor for the decline in the $H$. abyssinica population. Residential area expansion led to a significant loss of forest land as more people needed more lumber to build their houses. This ultimately created a big pressure on the surrounding forest. In addition, the extent of communities' involvement in agriculture seems to be increasing in all of the study sites. Informants categorized possible causes with the greatest impact on the depletion of $H$. abyssinica population as due to: heavy utilization i.e. selective cutting for (1) timber, (2) furniture, (3) house construction, (4) firewood use (5) medicine and (6) all other uses combined.

Heavy grazing and browsing impact from both livestock and wild animals was also mentioned as a reason that hampers the growth of young seedlings. Uncontrolled fire setting was another cause mentioned by informants. In many instances communities set fire to stimulate a new herbaceous growth to be used as livestock fodder but sometimes the fire burns trees and destroys large areas. In addition, trees may be killed by debarking, as this has been observed in the Kofele area. There, some $H$. abyssinica trees were found debarked. Reasons could be the extraction of bark for medicine or a systematic way of killing the whole tree. The effort to conserve the species in the study areas seems minimal. Although all informants have reported their interest, only few 30\% in Kofele, 26\% in Bale, and 7\% in Debark sites have actually planted $H$. abyssinica trees in their home garden. They explained that they usually transplanted seedlings from nearby forests to their backyards. Management practices included watering, fencing and adding organic fertilizer to the seedlings. Conversely, the majority of informants (74\% in Bale, $70 \%$ in Kofele and 93\% in Debark) explained that even if they have the interest they were 'not able' to plant $H$. abyssinica trees. Lack of seedlings is one of the reasons for not planting. Although they were not capable enough to find as many seedlings as they would like to have some informants were able to collect and transplant wild seedlings from 
the forest but the seedlings did not survive due to frost and livestock pressure. In addition, the community usually prefer to plant fast growing exotic species such as Eucalyptus spp.

By and large, respondents in all study sites highlighted the importance of $H$. abyssinica in their community. Because of its role in the society, people in Bale and Kofele areas described $H$. abyssinica as 'Hangefa Muka' meaning 'one of the oldest and most respected trees'. However, its population is drastically declining, and therefore, they would like to plant seedlings and carry out appropriate management activities. Consequently, they call for support from agricultural bureau or any other development organizations to get seedlings. Moreover; they suggested that carrying out an extensive awareness creation effort in their localities is timely. Plantation activities carried out around Debark and Kofele sites indicate some awareness, but should be further intensified. Providing continuous care for seedlings and setting up of protective boundaries against livestock browsing should be encouraged.

\section{Conclusion}

Communities in the study areas highly value Hagenia abyssinica for its medicinal properties. Though all parts of this medicinal plant are important to local communities, the most frequently used and mentioned part are the flowers, which carry anthelmintic properties, and are used against intestinal parasites (e.g. tapeworms). Hagenia is also used as veterinary medicine against many livestock ailments. Harvesting time, amount, purpose and prescriptions are found to be different among the study sites. Current utilization of $H$. abyssinica could be the result of a continued dependence of local communities on the species for their medicinal need. $H$. abysinica is marketable thus provides the opportunity to raise household income. This study has shown that returns from selling mainly its dried flowers are important, particularly to the poor households. Even though $H$. abyssinica offers diverse products, the tree population is in decline due to anthropogenic factors. This study provides insight into the local importance of $H$. abyssinica as well as the degree of threat on its population. The scarcity of the species in the locality was mentioned by all respondents. People recall their past time experiences and compare those to the present day situation of local resource abundance. Recalling the vegetation cover of their sites informants in the studied areas (especially in Debark) strongly suggests that deforestation of $H$. abysinica has been significant in the area. In all study sites, the extent of communities' involvement in agriculture was found to be high and seems to be increasing. This could result in more and substantial losses of $H$. abyssinica population which could ultimately lead to the fading away of the indigenous knowledge associated with the species.

Knowledge about identification, harvesting, preparation and utilization methods is still maintained within the community but in general, interest towards utilizing the traditional medicine is diminishing among many especially with younger people. Despite its widespread use kosso medicine is found to be harmful to health particularly when it is taken in large quantities. The prevalence of gastrointestinal upset following consumption is leading the majority of people in the study sites to reduce, modify way of intake or stop drinking completely. Kosso medicine is note taken by the majority of informants because of its side effects; some however (especially women and elderly people) still utilizing it. This may perhaps help to ensure the maintenance of knowledge on the species. In conclusion, it is useful to assist communities to document their knowledge. Moreover, averting illegal cutting and allowing natural regeneration of the population by protecting young seedlings from human and livestock destruction can help conserve this species. Creating public awareness and communitybased management is timely and the current plantation activities that are carried out in the study sites should be further encouraged.

\section{Acknowledgements}

The authors gratefully acknowledge Austrian Exchange Service (ÖAD) for financial support. The logistic support from Ethiopian Institute of Agricultural Research (EIAR) is highly appreciated. We would like to express our deepest gratitude to the informants for sharing with us their time and knowledge. Many thanks are due to Abdurahman Wario, Temesgen Yohannes, Demissew Nigatu, Yalemget and people who assisted us in many ways during data collection.

\section{Author details}

${ }^{1}$ University of Natural Resources and Applied Life Sciences, Department of Forest and Soil Sciences, Institute of Forest Ecology, Peter Jordan-Strasse 82, 1190 Vienna, Austria. ${ }^{2}$ University of Natural Resources and Applied Life Sciences, Department of Sustainable Agricultural Systems, Division of Organic Farming, Working Group: Knowledge Systems and Innovations, Gregor-Mendel-Strasse 33, 1180 Vienna, Austria.

\section{Authors' contributions}

BA and GG conceptualized and designed the study. The corresponding author collected field data and drafted the manuscript. CB participated in the enrichment of the manuscript. All authors read and approved the final manuscript.

\section{Competing interests}

The authors declare that they have no competing interests.

Received: 20 May 2010 Accepted: 11 August 2010

Published: 11 August 2010

\section{References}

1. Raedeke AH, Rikoon JS: 'Temporal and spatial dimensions of knowledge: Implications for sustainable agriculture'. Agriculture and Human Values 1997, 14:145-158.

2. Berkes F, Colding J, Folke C, (Eds): Navigating Social-Ecological Systems: Building Resilience for Complexity and Change. Cambridge University Press 2003, 393. 
3. Ellen $\mathrm{R}$, Harris $\mathrm{H}$ : Indigenous environmental knowledge and its transformations: critical anthropological perspectives. Hardwood, Amsterdam, The NetherlandsEllen RF, Parkes P, Bicker A 2000, 356, 'Introduction', 1-33.

4. Warren DM, Slikkerveer LJ, Brokensha D: The Cultural Dimension of Development-Indigenous Knowledge Systems. In Intermediate Technology Publications, LondonWarren DM, Slikkerveer LJ, Brokensha D 1995, 'Introduction'.

5. WHO: Traditional Medicine., Fact Sheet No 1342003.

6. Gebremariam T, Asress K: Applied Research in Medicinal Plants. proceedings of National Workshop on Biodiversity Conservation and Sustainable Use of Medicinal Plants in Ethiopia: April 28-May 1998 Biodiversity Institute, Addis Ababa.

7. Abebe D: Traditional medicine in Ethiopia: the attempts being made to promote it for effective and better utilization. SINET 1986, 9:61-69.

8. Abebe $D$, Ayehu A: Medicinal plants and enigmatic health practices of northern Ethiopia B. S. P. E. Addis Ababa, Ethiopia 1993.

9. Gedif T, Hahn H: The use of medicinal plants in self-care in rural central Ethiopia. Journal of Ethnopharmacology 2003, 87:155-161, (2003).

10. Giday M, Teklehaymanot T, Animut A, Mekonnen Y: Medicinal plants of the Shinasha, Agew-awi and Amhara peoples in northwest Ethiopia. Journal of Ethnopharmacology 2007, 110:516-525.

11. Lulekal E, Kelbessa E, Bekele T, Yineger H: An ethnobotanical study of medicinal plants in Mana Angetu District, southwestern Ethiopia. Journal of Ethnobiology and Ethnomedicine 2008, 4:10.

12. Tadesse M, Demissew S: Medicinal Ethiopian plants: inventory, identification and classification. Plants Used in African Traditional Medicine as Practiced in Ethiopia and Uganda Asfaw Z: Addis Ababa UniversityEdwards S Addis Ababa 1992, 1-19, Botany 2000. East and Central Africa: NAPRECA Monographs Series No. 5

13. Teklehaymanot T, Giday M: Ethnobotanical study of medicinal plants used by people in Zegie Peninsula, northwestern Ethiopia. Journal of Ethnobiology and Ethnomedicine 2007, 3:12.

14. Yineger $\mathrm{H}$, Kelbessa $\mathrm{E}$, Bekele $\mathrm{T}$, Lulekal E: Ethnoveterinary medicinal plants at Bale Mountains National Park, Ethiopia. Journal of Ethnopharmacology 2007, 112(3):55-70.

15. Beentje HJ: Kenya trees, shrubs and lianas. National Museums of Kenya, Nairobi 1994, 722

16. Abebe G, Dawson $\sqcup$, Detweiler G, Gipson TA, Sahlu T: Hagenia abyssinica (Kosso) for internal parasite control in goats. The opportunities and challenges of enhancing goat production in East Africa E (Kika) de la Garza Institute for Goat research, Langston University, Langston, OK, Debub University, Awassa, Ethiopia, 10-12 November, 2000Merkel RC, Abebe G, Goetsch AL 190-195.

17. Desta B: Ethiopian traditional herbal drugs. Part I: Studies on the toxicity and therapeutic activity of local taenicidal medications. Journal of Ethnopharmacology 1995, 45:27-33.

18. Giday $M$, Asfaw Z, Elmqvist T, Woldu Z: An ethnobotanical study of medicinal plants used by the Zay People in Ethiopia. Journal of Ethnopharmacology 2003, 85:43-52.

19. Fassil Kibebew, Getachew Addis: Utilization and conservation of medicinal plants in Ethiopia. Proceedings of the Workshop on Development Utilization of Herbal Remedies in Ethiopia; Ethiopian Health and nutrition Institute, Addis Ababa 1996, 46-52.

20. Federal Democratic Republic of Ethiopia (FDRE): Forestry Proclamation (NO. 94/1994).

21. Pankhurst R: An historical examination of traditional Ethiopian medicine and surgery. Ethiop Med J 1965, 3:151-172.

22. Samuel TDheressa: Production and Reproductive Performance of Gobe Ranch from year 1994-2006 \& its Challenges and Opportunities, Gobe, Ethiopia. 2007.

23. Hillman JC: Bale Mountains National Park Management Plan. Ethiopian Wildlife Conservation Organization (EWCO), Addis Ababa 1986, 250.

24. Mohr PA: The Geology of Ethiopia Addis Ababa. Haile Selassie University Press 1963.

25. Martin GJ: Ethnobotany: A Methods Manual. Chapman and Hall; London 1995

26. Cotton CM: Ethnobotany: Principles and Applications. Chichester, New York: John Wiley and Sons, Ltd 1996.

27. ISE: International Society of Ethnobiology Code of Ethics.[http://www. ethnobiology.net/global_coalition/CoE-Eng.php].
28. Azene BT, Brinie A, Tegnäs B: Useful trees and Shrubs for Ethiopia: Identification, Propagation and Management for Agricultural and Pastoral Communities. Regional Conservation Unit, Swedish International Development Authority (SIDA) 1993.

29. Negash L: Indigenous Trees of Ethiopia: Biology, uses and propagation techniques. Printed by the SLU Reprocentralen, Umeå, Sweden 1995.

30. Wondimu T, Asfaw Z, Kelbessa E: Ethnobotanical study of medicinal plants around 'Dheeraa' town, Arsi Zone, Ethiopia. Journal of Ethnopharmacology 2007, 112(1):152-161.

31. Yineger $\mathrm{H}$, Yewhalaw D: Traditional medicinal plant knowledge and use by local healers in Sekoru District, Jimma Zone, southwestern Ethiopia. Journal of Ethnobiology and Ethnomedicine 2007, 3:24.

32. Yineger $H$, Yewhalaw D, Teketa D: Ethnomedicinal plant knowledge and practice of the Oromo ethnic group in souwthwestern Ethiopia. Journal of Ethnobiology and Ethnomedicine 2008, 4:11.

33. Fluckiger FA, Buri E: Beiträge zur Kenntniss des Kosins. ARCHIV DER PHARMACIE 205 1874, 193-205.

34. Lounasmaa M, Widen C-J, Huhtikangas A: Phloroglucinol Derivatives of Hagenia abyssinica. II. The structure determination of kosotoxin and protokosin. Acta chemica scandinavica series B 28 1974, 1200-1208.

35. Mesfin T, Obsa T: Ethiopian traditional veterinary practices and their possible contribution to animal production and management. Review of science and technology 1994, 13:417-424.

36. Giday M, Ameni $\mathrm{G}$ : An ethnobotanical survey on plants of veterinary importance in two woredas of Southern Tigray, Northern Ethiopia. SINET Ethiopian Journal of Science 2003, 26:123-136.

37. Addis $G$, Abebe $D$, Urga K: A survey of traditional medicine in Shirka District, Arsi Zone, Ethiopia. Ethiopian pharmaceutical journal 2001, 19:30-47.

38. Balemie K, Kelbessa E, Asfaw Z: Indigenous medicinal plants utilization, management and threats in Fentale area, Eastern Shewa, Ethiopia. Ethiopian Journal of Biological Science 2004, 3:37-58.

39. Tadesse M, Hunde D, Getachew Y: Survey of medicinal plants used to treat human diseases in Seka Cherkosa, Jimma Zone, Ethiopia. Ethiopian Journal of Health Sciences 2005, 15:89-106.

40. Rokos L: Eye complications in poisoning caused by "Kosso" (Hagenia abyssinica). Journal of Ethiop Med 1969, 7:11.

41. Amare Getahun: Some Common Medicinal and Poisonous Plants used in Ethiopian Folk medicine. Faculty of Science, Addis Abeba University, Ethiopia 1976.

42. Dharani N: Field guide of common trees and shrubs of East Africa. Struik Publishers, Cape Town 2002.

43. Klitina SE: 'Clinical picture and treatment of patients suffering from poisoning caused by Kosso collection of research work of the Soviet Red Cross Hospital in Addis Ababa', $4^{\text {th }}$ issue, 1965, 61.

44. Bishaw B: Attitudes of modern and traditional medical practitioners toward cooperation. Ethiop Med J 1990, 28:63-72.

doi:10.1186/1746-4269-6-20

Cite this article as: Assefa et al: Ethnomedicinal uses of Hagenia abyssinica (Bruce) J.F. Gmel. among rural communities of Ethiopia. Journal of Ethnobiology and Ethnomedicine 2010 6:20

\section{Submit your next manuscript to BioMed Central and take full advantage of:}

- Convenient online submission

- Thorough peer review

- No space constraints or color figure charges

- Immediate publication on acceptance

- Inclusion in PubMed, CAS, Scopus and Google Scholar

- Research which is freely available for redistribution 